\title{
Establishing conversation spaces in hastily formed networks: the worst fire in modern Swedish history
}

\author{
Jonas Lundberg Associate Professor, Department of Science and Technology \\ Eva K. Törnqvist Associate Professor, Department of Thematic Studies \\ Simin Nadjm-Tehrani Professor, Department of Computer and Information Science, \\ Linköping University, Linköping, Sweden
}

In presenting examples from the most extensive and demanding fire in modern Swedish history, this paper describes challenges facing hastily formed networks in exceptional situations. Two concepts that have been used in the analysis of the socio-technical systems that make up a response are conversation space and sensemaking. This paper argues that a framework designed to promote understanding of the sensemaking process must take into consideration the time at which as well as the location in which an individual is engaged in an event. In hastily formed networks, location is partly mediated through physical systems that form conversation spaces of players and their interaction practices. This paper identifies and discusses four challenges to the formation of shared conversation spaces. It is based on the case study of the 2006 Bodträskfors forest fire in Sweden and draws on the experiences of organised volunteers and firefighters who participated in a hastily formed network created to combat the fire.

Keywords: conversation space, cooperation, crisis, hastily formed networks, sensemaking

Published on September $5^{\text {th }}$, 2014, in the journal Disasters 38 (4):790-807. doi: 10.1111/disa.12076. Overseas Development Institute and Blackwell Publishing. Pre-print version - page numbers do not correspond to the definite version. The definitive version is available at www.blackwell-synergy.com.

\section{Introduction}

The purpose of this paper is to analyse the influence of time and location on sensemaking in hastily formed networks, and to identify and discuss challenges to the formation of shared conversation spaces.

\section{The 2006 Bodträskfors forest fire}

It is Thursday night, 11 August 2006, near Bodträskfors, Sweden. A caller tells the emergency services about a fire, but the operators take no action as they assume the smoke is coming from the remains of an extinguished fire, which the night staff at the medical centre have seen rising from the forest. Yet, some hours later, on Friday morning at 6:05 a.m., another call comes in and a couple of part-time firefighters, who were involved in the final

Lundberg, J., E.K. Törnqvist, and S. Nadjm-Tehrani. 2014. "Establishing conversation spaces in hastily formed networks: the worst fire in modern Swedish history." Disasters 38 (4):790-807. doi: 10.1111/disa.12076. 
extinction of another fire in the area, are assigned to determine the origins of the smoke. It takes a while before they localise the fire, but about an hour after the call, they have found it and begin to fight it with the equipment available in the vehicle they drove to the scene. At that time, the burning area is small, about $300 \mathrm{~m}$ by $20 \mathrm{~m}$. Three additional firefighters join together with two volunteers from the local community. Through the morning hours, they repeatedly request additional backup. When fire and rescue personnel from the Boden Municipal Rescue Service arrive at 10:13 a.m., the assessment is that the team is getting the fire under control and the first group is given a break. Excerpt 1, taken from the joint (unpublished) logbook, describes what happened next:

\section{Excerpt 1}

When the water is turned on, it doesn't work on the right side and it turns out that one of the hoses has burnt through. Everyone runs to help. Just then, the wind kicks up and right in the midst of the firefighters, ground fires blow up in various spots in the 1.5-2-m-high brush and for 50-60 m ahead of them. The ground is usually wet, but not this summer. Very quickly, the fire becomes uncontrollable. The incident commander on the scene orders the team to save what can be saved and for everyone to move back to the road. Everyone runs to escape the fire and two firefighters suffer facial burns. An ambulance is called, but no one is seriously injured. The team attempts to stop the fire and calls for more help. Hoses and connections are destroyed by the fire.

Excerpt 1 reveals part of the initial phase of what was to become the largest fire in modern Swedish history (see Figures 1 and 2).

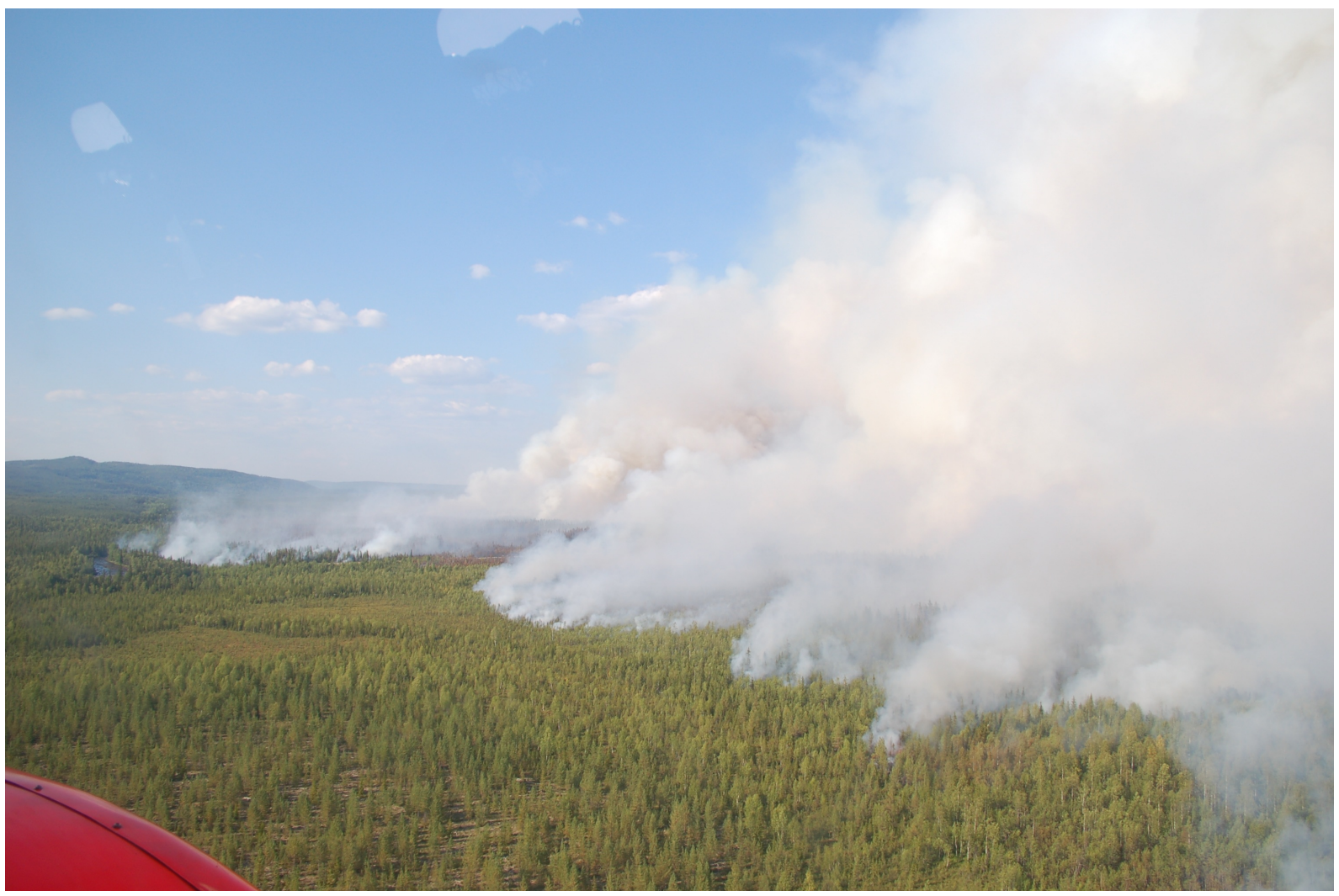

Figure 1 The fire edge seen from a helicopter.

Photo: (C) Boden Municipal Rescue Services 


\section{Latent conditions}

It was unusually hot in northern Sweden in 2006, and August was among the five hottest months in 100 years. A total of 264 fires were reported in the area that summer, several of which were burning at the same time as the fire in Bodträskfors.

At its peak, the Bodträskfors fire covered 1,900 ha of forest within a boundary area of 3,000 ha. In Figure 2, the affected area extends roughly to the Lule river on the east and to the thick borderline on all other sides. Although it began as a surface fire, it developed into crown fires that were jumping as high as $100-150 \mathrm{~m}$. As a result, and due to increasing winds as well as burnt hoses, the fire spread rapidly, extending past the established fire lines on several occasions. Large quantities of supplies were used during the response, including $80 \mathrm{~km}$ of hose; it took four lorries to transport the supplies back to the original storage site. The total cost of the fire reached an estimated SEK 75-100 million (\$10-13 million) (SRSA, 2006).

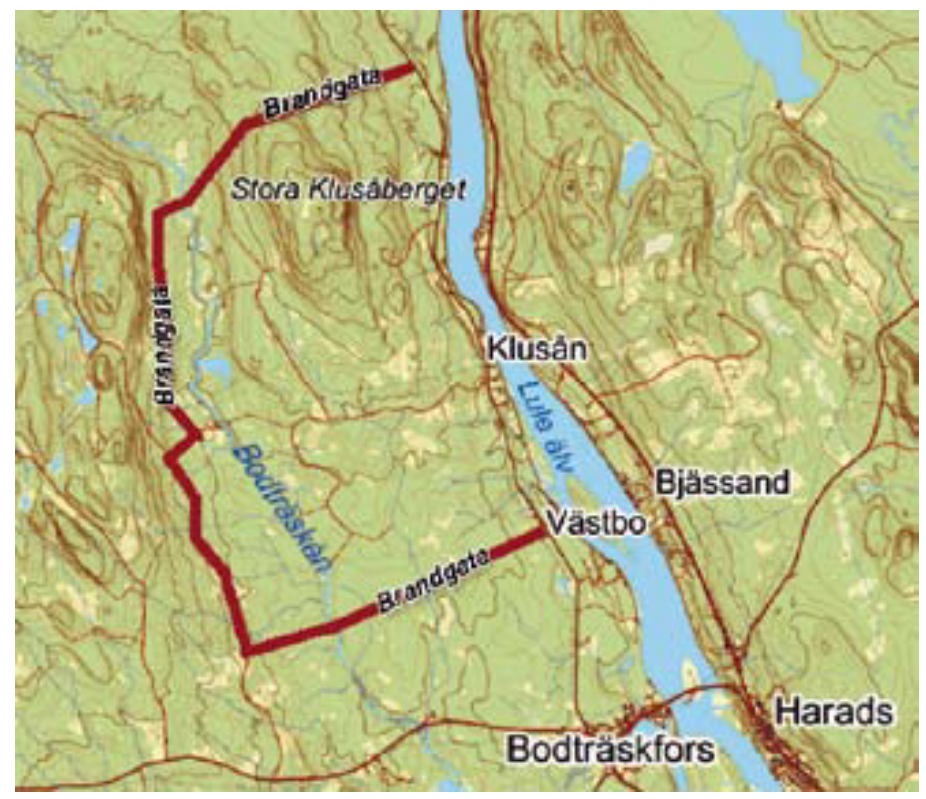

Figure 2 Extent of the fire.

Source: (C) Boden Municipal Rescue Service

\section{Method}

While many different players were involved in fighting the fire, this study focuses on two of them: the local Municipal Rescue Service, or MRS, and the Voluntary Resource Group, or VRG. The study is based on information gathered through group interviews with MRS and VRG members as well as texts, such as a joint logbook kept by the organisations involved. The research team selected these players because they are to a certain extent representative of the two extremes among groups that may participate in a hastily formed response network in the event of an exceptional incident.

While both players are locally based, their conditions for performing their missions differ. The MRS comprises professionals who have been trained to provide specific rescue services. 
In contrast, the VRG, which seldom participates in emergency response operations, is heterogeneous in terms of training and experience.

The VRG consists of volunteers who pitch in when something extraordinary has occurred, especially in their home municipality. The group may be called on to assist with evacuations, raising awareness, providing compassionate support to victims and administrative and other practical tasks. VRG members are released from their usual occupations for varying periods, and not always at the same time. While they may be trained for the tasks at hand, they are motivated to participate by a wish to serve the community. The VRG recruitment process places weight on maintaining the variety of experience, training and personal characteristics necessary for the diverse tasks the group may be asked to perform.

The tasks undertaken by the MRS during the fire were similar to those encountered in their day-to-day work; due to the scope of the incident, however, they required support from other professional and voluntary organisations, including the VRG.

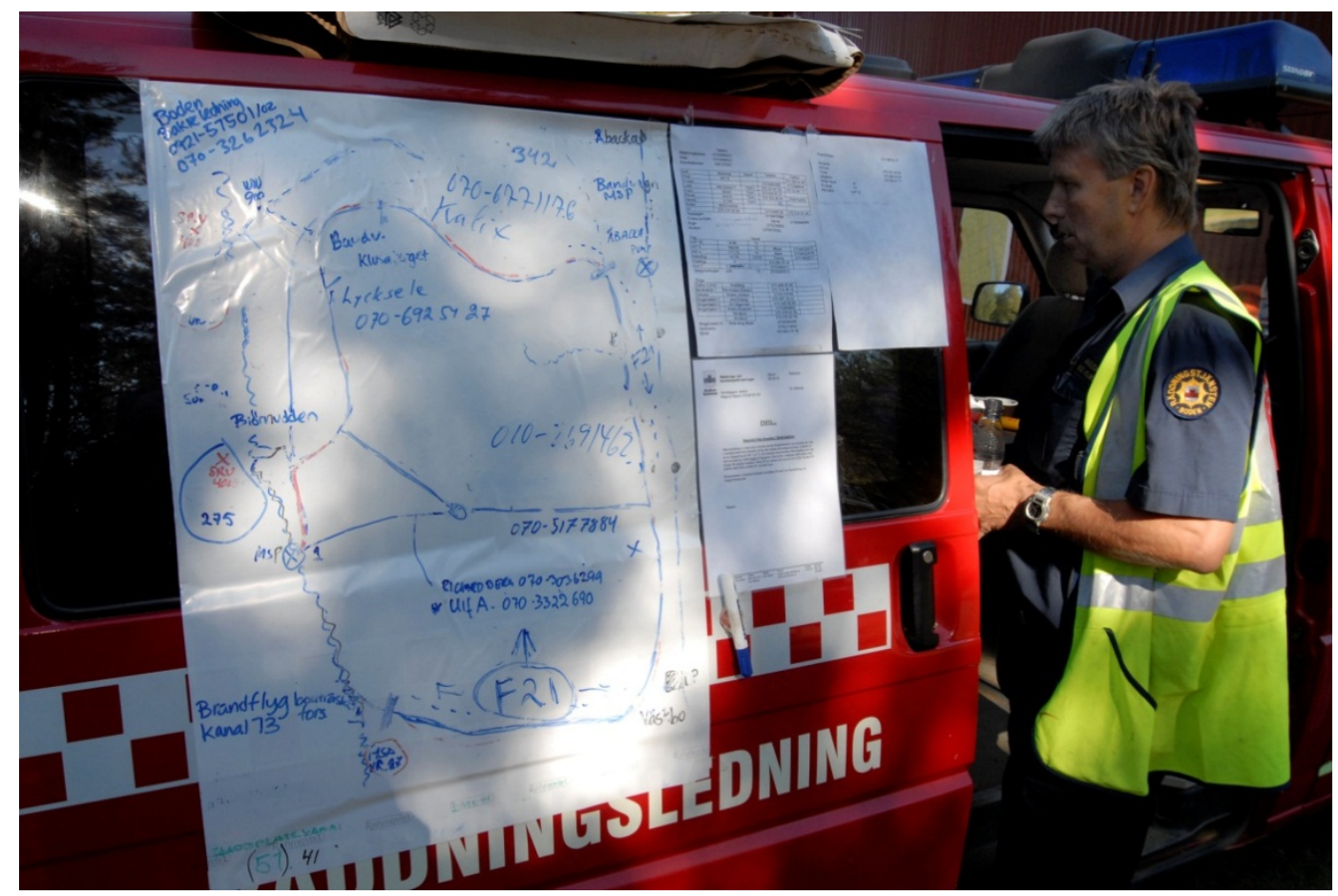

Figure 3 The MRS forward command centre at Västbo.

Photo: (C) Staffan Nygren/Norrbottens Museum

The research team conducted five group interviews with a total of 18 people: three group interviews with the local MRS personnel and two group interviews with members of the local VRG. Four of the groups comprised four participants each. The fifth interview was conducted with two MRS incident commanders; while one of them acted as forward commander (at Västbo, see Figure 2), the other served as rear commander with overall responsibility for the mission, supported by a command staff (in Boden). Figure 3 shows the forward command centre with one of the informants. When the fire started, only one incident commander was on duty, as is typical during normal operations.

All interviews were semi-structured and recorded; each lasted two to three hours. Group participants were recruited via the respective organisations. All MRS informants had 
participated in the actual firefighting in Bodträskfors. Two VRG informants had not personally experienced the fire. In addition to the narratives presented by the informants, the research team also had access to the joint logbook and to documentation from a VRG debriefing seminar.

\section{Analysis: a complete surprise}

Many fires had been put out successfully in the weeks preceding the Bodträskfors fire. The firefighters who responded to the fire in Bodträskfors initially took a standard approach, constructing fire lines, laying hose and so on. They drew on previous experience in trying to identify patterns and managing the new fire. In interviews, the firefighters and commanders acknowledged that they had initially believed they were tackling a regular fire:

\section{Excerpt 2}

-We had had several [fires] before, which we had dealt with.

-Nothing strange, we have the skills.

The approach they took reflects the one taken by ground commanders in a process known as recognition-primed decision-making. Experts draw on familiar cues to formulate goals, actions and expectations regarding the development of a situation (Klein and Calderwood, 1991). In this respect, the situation resembles the Mann Gulch disaster, which was also expected to be a regular fire (Weick, 1993). To understand that fire, Weick discusses the concept of structuring, which concerns the relationship between social construction and contextual constraints. Social construction is about meaning, about 'interaction patterns that stabilise meaning by creating shared interpretive schemes' (Weick, 1993, p. 645). At the core of contextual constraints is 'a framework of roles, rules, procedures, configured activities and authority relations that reflect and facilitate meanings' (Weick, 1993, p. 645). The importance of structuring in the Bodträskfors forest fire grows as the event unfolds.

Denning (2006) uses three aspects to define a situation: knowledge of the time and place, knowledge of what to do, and knowledge of the response structure. He describes a routine situation, such as the one the firemen alluded to in Excerpt 2, as a known unknown. The situation is characterised by people knowing what do through known response structures, but not knowing the time or place in advance. If the time and place had also been known in advance, the situation could have been referred to as a known known.

As the Bodträskfors fire developed, it soon became clear that circumstances were unusual and that the accustomed response would not be appropriate, as revealed by the comments of firefighters and commanders (see Excerpt 3).

\section{Excerpt 3}

- So big, so hard to prepare, no water, so dry.

- It's hard to know how big it might become.

- It was so big, so big, so big.

- It felt ... hopeless to stand there with the hose, so hopeless.

-We couldn't grasp that it had moved; we had it confined, it was essentially under control. 
This set of responses reflects 'situation awareness' - the ability to perceive cues from the environment, comprehend their meaning and project their status into the future (Endsley, 1988). Thinking patterns that result in situation awareness can be described in terms of 'schema' - templates that organise previous experiences to enable an understanding of new information (Stanton et al., 2009). In Bodträskfors, templates or schema appear to have hindered rather than helped the responders. The initial misjudgement of the situation is consistent with previous studies of expert problem detection. As Klein et al. (2005) describe, problem detection can sometimes be hindered by expertise and the expectations it brings.

The firefighters in Bodräskfors perceived the dynamic development of the fire as the main difference between this event and their previous operations. The fire spread rapidly across large areas, including marshes, which are normally a limiting factor due to the wetness of the ground. Sparks jumped, hoses burned, someone was injured and vehicles had to be moved urgently because personnel were in danger of being trapped by the fire. Over a short period of time, a series of latent conditions were revealed. Parallels can be drawn to developments during and immediately following the triggering events in man-made disasters, such as mining accidents (Turner, 1978).

Previous experience told the firefighters that the actions they had taken should have led the fire to be extinguished. Instead, they experienced a moment of complete surprise, a transition from facing a known unknown to confronting an unknown unknown (Denning, 2006; see Excerpt 4). As the situation escalated, the firefighters went from merely not knowing the time and place (known unknown) to taking on the additional problems of not knowing what to do and not knowing the response structure (unknown unknown). Westrum (2006) takes a similar approach to defining situations, dividing them into regular, irregular and unexampled events.

In analogy to the abovementioned Mann Gulch disaster, this shift closely resembles what Weick describes as a cosmology episode in which 'both the sense of what is occurring and the means to rebuild that sense collapse together' (Weick, 1993, p. 633).

When previous experience is inadequate to cope with what is happening, confusion or sometimes even panic may ensue, as shown in Excerpt 4.

\section{Excerpt 4}

We lost it. One of the firemen took off and I grabbed him and asked him: 'Where are you going?' He was about to run straight into the fire. He had no idea which direction he should run.

Interestingly, Weick describes a very similar episode in the Mann Gulch disaster, in which a fireman who had sat down in a bush was removed from it by a fellow firefighter (Weick, 1993). From this moment on, however, the events in the Bodträskfors fire take a different turn than in the Mann Gulch disaster. While the group was falling apart in the Mann Gulch disaster, many organisations attempted to form a whole in Bodträskfors.

\section{A delayed complete surprise: a rift in the conversation space}

The firefighters were not the only ones who initially saw the fire as yet another one in a long series of fires that they had previously responded to. On receiving the first reports about the fire, the incident commander on duty — whose title was subsequently changed to 'forward command' - ordered the crew at the scene to 'complete the mission'. He was about $60 \mathrm{~km}$ 
away at the MRS command and control centre. What he did not understand was what the situation looked like for the firefighters then and there; that is, he lacked what has been termed requisite interpretation - the ability to grasp a situation based on information about it, or to 'see the facts of an accident or disaster and actually accept that it happened and respond properly' (Lundberg and Johansson, 2006, pp. 5-6).

One of the firefighters at the scene described the situation as follows:

\section{Excerpt 5}

It was so huge. It was burning for five or six hundred metres in one direction and just as far in the other. It was burning as far as the eye could see, ten metres up in the treetops. You felt powerless with 800 litres of water in a dozer and a garden hose. There wasn't a lot you could do.

Numerous studies have considered the issue of not being able to grasp situations at other places or in other organisations. To understand this delay, it is useful to turn to the notion of conversation space (Denning, 2006). In this context, Denning posits that 'effectiveness [...] depends as much on the participating people and organizations as it does on the communication system through which they interact' (Denning, 2006, p. 18). He describes conversation space through the facets of physical systems, such as telephones and meeting places; players, as defined through roles, competences and authorities; and interaction practices, such as rules for planning and coordination. These facets resemble the notion of contextual constraints in that they restrict and enable social construction; they are also related to what Weick calls structuring.

Many of these issues have been studied elsewhere. For instance, Lundberg and Asplund (2011) describe five communication problems in crisis response and the respective published technical solutions. The five problems can be associated with two of Denning's facets:

- technical infrastructure (physical systems);

- situation awareness (interaction practices);

- communication paths (interaction practices);

- form and content of messages (interaction practices); and

- negotiation of common ground (interaction practices).

A detailed examination of the problem of the form and content of messages was undertaken in a study of crisis communication (Kruke and Olsen, 2011). The study finds that field notes overloaded with detail were problematic at the organisational blunt end. The notions of 'sharp' and 'blunt' ends are often used in comparisons of decision-making between different organisational levels. In relation to terms used by Denning, these ends relate to the authority and roles of players. As Reason (1997) puts forth, in organisational hierarchies, decisions are made at the blunt end - which is more remote from the situation in question - and affect conditions at the sharp end. An important point is that many different sharp-end-blunt-end relations may exist in multilevel organisations.

Complicating matters, Woods (2006), in a discussion of resilience, uses the similar term cross-scale interactions to indicate effects of decisions that go downwards in an organisation as well as those that go upwards. Furthermore, a study of the Victorian bushfires of 2009 discusses how to organise responses to extreme emergencies in terms of standardised roles (Leonard and Howitt, 2010)—-the players in Denning's terms. 
In Bodträskfors, the responders at the scene- the sharp end-were initially unable to convey the picture of the situation to the MRS commander at the blunt end. The physical systemproviding mediation of voice-was insufficient on its own to bridge the physical distance. This observation mirrors the finding that verbal descriptions of fires may be less useful to fire crews on their way to a site than richer information, not least $\mathrm{n}$ an effort to avoid misunderstandings about the kind of situation they are likely to face on arrival (Landgren, 2004).

Furthermore, in Bodträskfors, there were no established interaction practices to facilitate a rapid transition from what Denning describes as the known unknown to the unknown unknown. The weaknesses of both the interaction practices and the physical system created a rift in the conversation space between different players. The issue of first-hand experience at particular times and places — and its key role in sensemaking — is explored below.

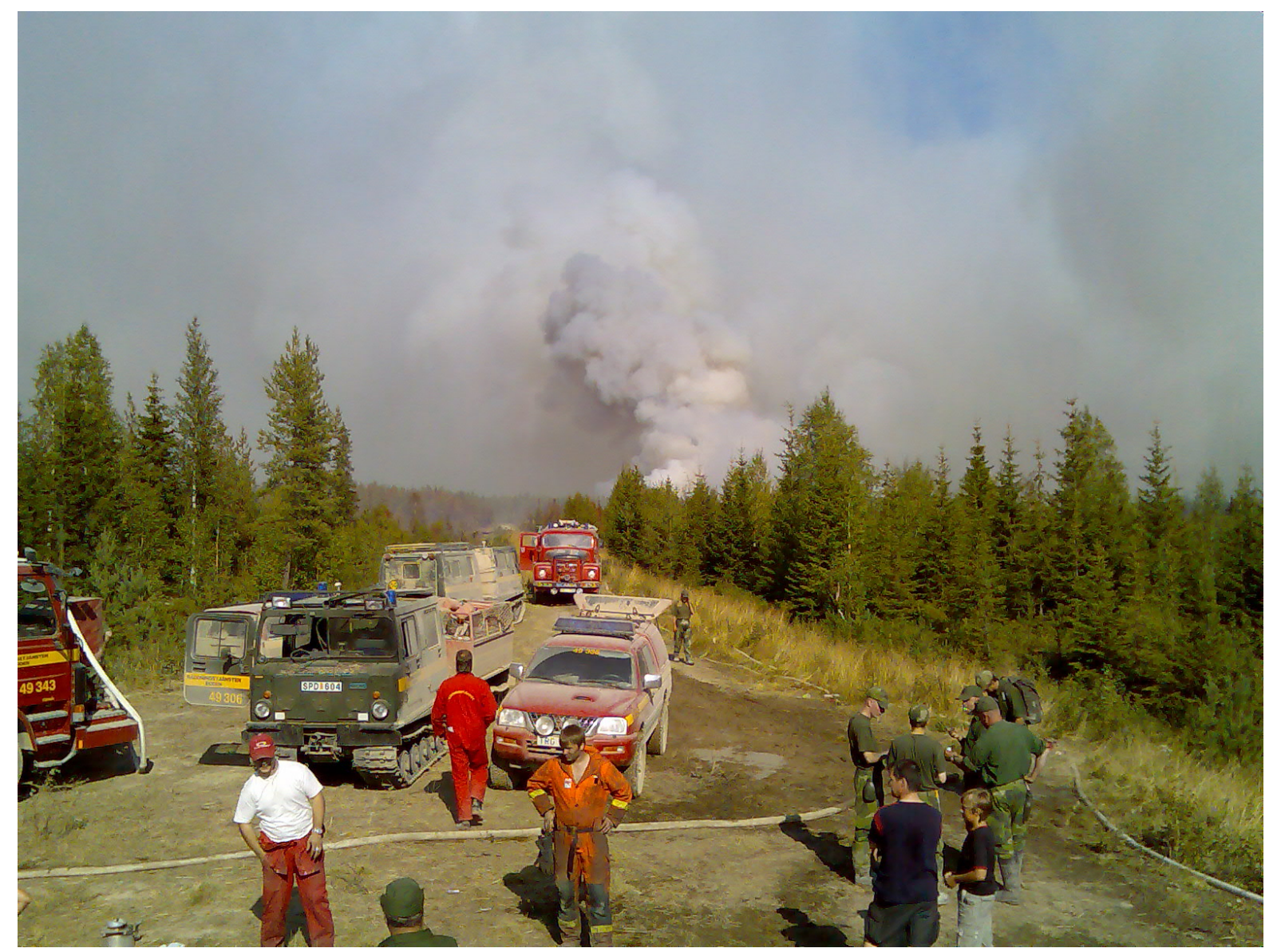

Figure 4 Components of the hastily formed network: the MRS, the Home Guard, forest companies and members of the public.

Photo: C Boden Municipal Rescue Service

\section{A hastily formed network}

Once the confusion of the initial phase had dissipated and responders understood that they could not rely exclusively on previous experience, the overarching need to extinguish the fire led to the establishment of a hastily formed network. 
Many different players, including forestry companies, helicopter services, the Swedish Armed Forces, the Home Guard and fire and rescue service personnel from Sweden and Finland became part of the hastily formed network (see Figure 4). Denning (2006) defines a hastily formed network as an organisational structure that is put together quickly in response to an emergency, crisis or urgent situation. It accepts no higher decision-making authority. No single organisation or agency has the capacity to meet the needs that arise. The network consists of a collection of entities that have expertise or local responsibility to help but that have not worked together before.

A maximum of 160 people were working during any 24-hour period, pulling 10-12-hour shifts. During the four weeks the fire was active, they worked a combined total of 750 person days. When the number of helicopters was at its peak, eight were used for air attack and two for other purposes, such as monitoring and transport.

The MRS established forward command at Västbo (see Figure 3); rear command remained at Boden. As Denning and Hayes-Roth (2006) note, people sometimes retain their organisational identities in hastily formed networks. This was a prominent feature during the fire in Bodträskfors, where the responders worked together in their usual groups. Firefighters who came in from other parts of the country and from Finland were not integrated with their peers from the nearby MRS in Boden. Instead, they formed their own work units in their own work areas with separate responsibilities. This approach is reflected in Figure 3, which shows a map used by the forward command, illustrating work areas for different firefighting groups.

The VRG was not involved in the actual firefighting. The group took on a support function for the incident command, fire and rescue crews and others so that they could concentrate on fighting the fire. Among other tasks, the group handled procurement of supplies and food transport, overseeing the delivery of about 160 meals per day to the mess location at forward command at Västbo (see Figure 2). Their mission also included providing transport for firefighters from and to the airport, the railway station, the fire line and the camps. In addition, VRG members were assigned to guard the closed roads and evacuated houses to prevent potential burglary or vandalism. The group performed various assignments for a total of 31 days. During the most intensive six days, the group worked in three shifts around the clock (Vennberg, 2006).

\section{Boundary emphasis}

Excerpts $6 \mathrm{a}$ and $6 \mathrm{~b}$ illustrate the partial isolation of the different organisations, emphasising the boundary between the locals and the firefighters who had come from elsewhere in Sweden.

\section{Excerpt 6a}

One of them [firefighters who came in from outside the district] was so afraid [of bears] that he refused to get out of the ATV [all-terrain vehicle].

\section{Excerpt 6b}

[They were] 'only interested in learning to chop down trees and drive an ATV and look for bears $[\ldots]$ but they did a lot of good.

This emphasis on a boundary between them and $u s$ is indicative of divergent conversation spaces. 


\section{A rift in the conversation space}

On the one hand, the separateness of conversation spaces between participating organisations was not perceived as a problem or disadvantage in terms of carrying out particular actions, due to the division of work between participating organisations (see Excerpt 7a).

On the other hand, as Excerpt $7 \mathrm{~b}$ illustrates, at least in the beginning it was difficult to make sense of developments and what other units were doing. The overarching strategy was perceived as fighting the fire 'here and there'. Responders perceived the coordination of the work and the sharing of situation awareness as lacking - reflecting interaction practices that belong to the overarching conversation space.

\section{Excerpt 7a}

We're used to working together, we know what we're supposed to do, work independently within the group and don't have to communicate much with others outside the group.

\section{Excerpt $7 b$}

Those first days, it was like nobody really knew what was going on, we tried to fight the fire kind of here and there and nobody knew what anybody else was doing - it was burning everywhere, you know.

\section{Mending the rift?}

The response to Bodträskfors fire underwent a significant transition: what began as local organisations dealing with a known unknown during regular work hours turned into a hastily formed network dealing with an unknown unknown. This transition presented challenges to the different players, in particular in establishing a conversation space. The following sections describe ways in which the rift in the overarching conversation space was mended over time, and ways in which new rifts emerged.

\section{From radio communication to runners}

As noted, Denning presents physical systems for communication as a component of the conversation space. During the Bodträskfors fire, conversation spaces had to be established between groups at different locations. One option that emerged was open radio communication, which allows people to listen to what others are saying. Listening to conversations about the situation from other groups could have contributed to mending the rift between players who were located in different places in the hastily formed network.

Technically, the radios were working very well. Part of the terrain had poor coverage, but there was a radio relay station in the area. However, only one of the local MRS groups made use of radio relays. Complicating the situation, groups arriving from the outside had not been advised to bring their radio equipment and had not thought to take any with them (just as 
some did not bring firefighting gear suitable for forest fires either). The result was a shortage of portable radios, such that each group could borrow only one unit. Thus, although the VRG had practised their radio communicating skills, there were not enough devices available for all members. Vehicles - including helicopters-were also equipped with radios, but these could only be operated in the vehicles.

Consequently, people turned to an alternative option: improvisation. As previous studies have shown, improvisation of different kinds is a common feature of crisis response (Webb, 2004). In this case, they attempted to use their private mobile phones.

As it turned out, the distribution of information and communication with the MRS and the VRG occurred mainly on mobile telephones, most of which were private. That the power supply and communication towers largely worked as usual was thus a key factor. As shown in Figure 3, mobile phone numbers for each sector and for the rear command were written on the map used by the forward command. One of the sheets pasted to the right of the map provided mobile phone numbers and radio codes for contact with the sectors. The exception was the local MRS group that was familiar with radio relays; at the time the photo was taken, this group had not been assigned a mobile phone number.

The use of mobile phones for communication led to asymmetry in the flow of information and communication, for example, creating divergent conversation spaces and widening the rift between groups. During interviews, two MRS commanders confirmed that the asymmetry was problematic, noting that people driving into the area by car were not able to listen to updates regarding changes in the moving fire.

Although physical systems were functioning properly, a conversation space could not be readily established through the mobile phone network. MRS groups from northern Sweden could use their mobile phones, but the service provider of the southern MRS groups did not offer coverage in the area, which rendered their phones unusable. As a result, and in view of the fact that they had neither access to nor experience in using radios, these groups had to communicate face-to-face.

They improvised yet again, turning to the use of runners for short-distance communication. At times, contact was lost with one group or another, such that runners also had to cover long distances. The method was time-consuming, since one person often had to be deployed to go either on foot or by transport vehicle. On the one hand, this widened the gap further, adding yet another physical system for communication that could not be listened to by others, except for what the runner might hear in transit. On the other hand, this approach partially mended the rift in the conversation space by establishing practices that allowed some communication to occur.

\section{Sensemaking at the particular time and place of the fire}

The paper now considers some issues that at first sight might seem self-evident, or perhaps trivial. Yet the players discovered or understood their significance only once they had reached the fire. 
The fact that many of the responders used their personal mobile phones could have been beneficial, but the situation in which they operated differed markedly from normal settings. Several informants stated that it was difficult to hear the phones ring and to understand the person on the other end if they were close to the roaring fire. Screen size and lighting conditions at the scene also influenced whether a mobile phone is perceived as an enabler or as a constraint when information was sent in the form of texts or multimedia messages. The compactness of the mobile phone may constitute a constraint because it can be difficult to handle in situations when the user must wear protective gloves, for instance. Informants also mentioned the risk of relying on a handheld device that is so small and easy to drop without noticing it.

Why were these drawbacks not discovered in advance? As Excerpt 8 illustrates, the responders had not become aware of these issues during previous response missions. One factor was that the duration of past operations had been considerably shorter. Even though the fire did not affect the power supply in the Bodträskfors area, several informants from both groups mentioned problems with charging mobile phone batteries. The MRS also had battery problems with their mobile radios. Most of the responders were working where there was no access to electricity even under normal circumstances, but in shorter missions this had not been a problem.

\section{Excerpt 8}

-Do I have enough battery life left? I couldn't charge my mobile where I was. I had never needed batteries before. It wasn't such a large area, I could just shout to get hold of [the person I needed to communicate with].

-I don't think you should rely too much on the mobile phone, because all you have to do is move a little bit and you lose coverage.

The fire spread across partly rolling terrain, where mobile phone coverage was uncertain and where people sometimes operated in areas with uneven radio coverage; moving one metre or two in either direction could cause the loss of a signal. For some, this appears to have been a new experience. One MRS member said it was not amusing to be alone without access to communication in the face of a rapidly approaching fire, noting that no one had been able to hear radioed requests for help. A VRG member said that when she had not been contacted for several hours, she did not know whether she had been forgotten or whether people were unable to reach her. Her uncertainty only grew with respect to what was happening outside her immediate vicinity. The use of mobile phone networks deep in the forest thus meant that outgoing messages might not go through while incoming ones might not be noticed or might not arrive at all.

While the fact that most of the responders had not encountered such technical issues in previous, briefer operations helps to explain why such problems were not anticipated, another factor was the expectation that radios would be made available for communication.

Moreover, it might not be easy to fully grasp the consequences of such issues in advance, without experiencing the situation first hand. In this sense, the physical place may be seen as a key contextual constraint; to fully understand an issue, a person may need to be in that physical space, experiencing the event.

\section{The importance of being present at a physical location for sensemaking}


At the beginning of a shift, some members of the fire and rescue team as well as the VRG were given the opportunity to fly by helicopter across the entire area in order to form a picture of how the fire was developing and where the other crew members were working. During interviews, all of them emphasised how important the flyover had been in shaping their awareness of the total extent of the fire. A statement made by a responder who had not seen the fire and its extent from the air, but rather from the immediate area and via maps, stood in stark contrast to those of the flyover team (see Excerpt 9).

\section{Excerpt 9}

To this day, I still don't get how big it was.

As discussed, the interviews revealed that the best way to gain a solid understanding of the extent of the fire was to fly over the affected area. Those who were informed of the extent but who did not make any first-hand observations felt less aware of the scope of the situation. Greater awareness could not be conveyed by the conversation space established on the ground in the Bodträskfors area. Nor could technology or conversation practices be used to overcome physical location as a contextual constraint. In addition to emphasising the importance of first-hand experience, this case study also examines the shared practices of social construction between the VRG and the MRS.

\section{Sharing a physical location: converging conversation spaces}

Excerpts 10a and 10b highlight how sharing a physical location contributed to shared practices and to a partially shared conversation space, which helped to mend the rift between different organisations to a certain extent:

\section{Excerpt 10a}

The forward commander talked to people who went on a new shift. For instance, in the morning, there was a briefing. They then stood there by the map and talked about where it was most intense, and where the fire had restarted at locations they had thought were put out. He talked about what happened in the whole area. And we [the VRG] could also listen to that.

\section{Excerpt 10b}

Then the helicopter pilots sat down for a snack. If you [the VRG] sat down and talked to them, then you could ask them what they were doing, and they would tell you.

The excerpts reveal that VRG members who were present at the MRS briefings were free to listen in. In addition, members of both groups ate snacks in the same physical location, which allowed for informal chats between VRG members and helicopter pilots.

\section{Not sharing a physical location: diverging conversation spaces}

In contrast to Excerpts 10a and 10b, Excerpt 11 reflects a VRG participant's perception that there was a rift in the VRG conversation space despite the sharing of information practices, largely because she was posted in a different location than her peers.

\section{Excerpt 11}


They put me on guard duty somewhere in the middle of the forest, on a road, and I do not have a mobile phone number, nothing. They have a piece of paper, but it is attached to the table, and you have nothing to write on. There is no time, because you have to leave.

The informant argued that phone numbers were not made available to her before she went on guard duty in the middle of the forest. As above, the question arises as to whether such a situation could have been anticipated. Yet people who were at the mentioned table location described the situation in the following way:

\section{Excerpt 12}

We had a text that we put up, with all our mobile phone numbers. They were there, and if someone arrived then their name and number was added. So it was always in that list.

Based on these assertions, it appears that only individuals who were in the forest while the fire was raging could fully grasp the need for access to the list of phone numbers. Unlike the situation described in Excerpts 10a and 10b - in which VRG and MRS members shared situation updates in one location - the physical location was not shared in this latter instance. Just as sharing the place allowed the two separate groups to share a conversation space, not sharing a physical place allowed a rift to emerge within the VRG conversation space. As a result, the VRG did not share a common conversation space as they should have.

In the above examples, the physical systems for communication between locations - mainly mobile phones - did not fully compensate for the lack of a shared physical location. The variations in the accounts of what is essentially the same issue - a phone list on a tableindicate that VRG members at different locations were not able to construct the situation together. As Weick (1993) notes, social construction requires communication patterns. In terms of a conversation space, weaknesses in the physical system disrupted social construction. Yet the notion of conversation space also includes interaction practices. If interaction practices for the situation had been practiced in advance, the conversation space might have been powerful enough to facilitate social construction. The authority of the different players - another key notion in the theory of conversation space - was also important here. With greater authority, the VRG member could have demanded the provision of her own copy of the phone list before going to the position in the forest.

\section{Information overload and underload}

As stated above, the VRG participants did not always know where the others in the organisation were or what they were doing. The same can be said of MRS personnel (see Excerpts $7 \mathrm{a}$ and $\mathrm{b}$ ). This article has addressed this problem in terms of physical systems and experience. This section highlights aspects of information flow.

Some VRG informants said that there were gaps in the information chain, partly because it was unclear who should receive messages, requests or questions (see Excerpt 13a). This lack of clarity may have led some messages to be distorted and may have given rise to unnecessary misunderstandings. In contrast, MRS personnel did not perceive this to be a problem; instead, they attributed disruptions to a lack of accessibility (see Excerpt 13b).

\section{Excerpt 13a}


Communication did not always work well because you might call someone who had to call someone else and there was a gap somewhere. The message might not always get to where you wanted it to go and you got conflicting information. So, the information chain is probably another thing you have to think about.

\section{Excerpt 13b}

The mobile phones were going incessantly, that's for sure. Sometimes you couldn't get through; you got a constant busy signal. The system was probably overloaded.

On the one hand, informants emphasised the importance of a copious flow of information in making sense of a dynamic situation. Some experienced information underload (see Excerpts $7 \mathrm{~b}$ and 11) or conflicting information (see Excerpt 13a).

On the other hand, the respondents expressed fears about information overload. There is some danger that if all information is given to everyone involved, only a small part of it will be relevant to any recipient. As one informant asked: 'Out of all this, what do I need to know?'

Indeed, information overflow can make it difficult to identify relevant information. The findings of this study suggest that the solution is not to gather all information in one big flow that needs to be filtered by each individual. Instead, conversation spaces should be established in such a way as to allow people 1) to direct information at individuals (while preventing information overload) and 2) to listen to other people's conversations to gain awareness of what is happening (while preventing information underload).

This dual approach reflects a distinction between shared situation awareness (as requested by the VRG informant) and team situation awareness (as called for by the MRS informant). Shared situation awareness is about sharing aspects of a situation with people, whereas team situation awareness is limited to the understanding that is required for the task at hand (Stanton et al., 2009). Comfort (2007) further explores the issue of sharing information, presenting a dilemma between multi-way communication (which supports coordination) and one-way communication (which saves time).

\section{Summary and discussion}

This study exposes four major challenges to sensemaking in hastily formed networks. They are all related to time, space, and to the physical systems mediating the conversation space.

First, an important measure of the power of physical systems as mediators of conversation spaces is the extent to which they can convey first-hand experiences over a distance. This paper presents examples of situations in which it is important both to obtain first-hand experiences and to share them with people in other locations. A second measure relates to a responder's delay in comprehending an issue compared to those with first-hand experience. Another measure is the extent to which conversation spaces are associated with sharing a physical location (such as during the VRG and MRS briefings) or with belonging to a particular organisation when it is divided over different physical locations. 
Second, the problems with the use of mobile phones as a physical system for the conversation space point to a rift that was largely not mended. Although these problems may appear selfevident with hindsight, they only emerged as problems when responders were in the midst of the firefighting project. Training that allows people to experience issues first-hand may facilitate comprehension.

Third, established interaction practices did not work in the new context. Practices relating to maximising the use of equipment were lacking. Such practices may need to be shared throughout a hastily formed network to enable a conversation space. Examples might include contextual constraints such as using mobile phones when reception is unreliable, understanding when calls should be expected, or social construction, such as communication practices for successful voice-mediated conversations near a roaring fire.

Fourth, it seems that the responders did not or could not upgrade their mobile telephones through additional technology. A suitable physical system requires direct communication to address information overload (through the selection of recipients and selective listening) and mass communication to address underload (through listening to conversations as a way of gathering fuller awareness of events). Furthermore, whereas the familiarity with public safety radios tends to be relatively stable, that of personal mobile phones does not, partly because their design and functions change regularly.

The study shows that the groups discovered problems during the response operation rather than in advance, and that they relied on their personal mobile telephones. The physical system could thus usefully take the form of software-on-demand installed on normal consumer telephones. Ideally, such software would meet a variety of challenges encountered by responders, such as being sent out into the forest in a rush, as recounted by the VRG member who had not had enough time or authority to copy telephone numbers from a list. Since pen and paper were not readily available, software installations may not represent sufficient steps either. New solutions must also resolve relevant contextual constraints (such as the lack of authority and the lack of time).

The software would also need to be functional — and the telephones usable — when people have no network access, such as when SIM cards are incompatible, a provider does not offer coverage, or is overloaded. The abovementioned runners were not able to use their mobile phones because their SIM cards proved incompatible with the local network. Yet they could have connected directly to other telephones nearby, if software for that purpose had been installed on the telephones (Asplund et al., 2010). With such software, they could have used their telephones for short-distance communication, much like they might have used a radio. They could also have communicated with members of other groups during firefighting or even responders in helicopters flying overhead. This technology could thus have eliminated the need for runners. It should be noted that, much like in the case of the problem involving the list of phone numbers, the responders did not change their SIM cards although that would have been technically possible. Thus, deployment of software is not unproblematic; it needs a more reliable foundation than the mere insertion of compatible SIM cards.

\section{Conclusions}


Weick (1993) ends with a note that training and preparation might previously have focused too much on individuals instead of teams. This study aims to add training and preparation of organisations to that list, with a focus on enabling individual organisations working with a known unknown to merge into a hastily formed network targeting an unknown unknown.

As a starting point, this paper analyses how time and place affect sensemaking in a hastily formed network. In the network, place was partly mediated through physical systems, forming conversation spaces among some players with their interaction practices. With respect to training and preparation, this paper identifies and discusses four major challenges to the formation of shared conversation spaces in hastily formed networks. Further research is needed to find ways to meet those challenges.

\section{Acknowledgements}

The authors are grateful for the participation of VRG and MRS members in this study. This research was funded by the Swedish Civil Contingencies Agency (Myndigheten för samhällsskydd och beredskap).

\section{Correspondence}

Jonas Lundberg, Department of Science and Technology, Campus Norrköping, Linköping University, 60174 Norrköping, Sweden.

E-mail: jonas.lundberg@liu.se.

Eva Törnqvist, Department of Thematic Studies, Linköping University, 58183 Linköping, Sweden.

E-mail: eva.tornqvist@liu.se.

Simin Nadjm-Tehrani, Department of Computer and Information Science, Linköping University, 58183 Linköping, Sweden.

E-mail: simin.nadjm-tehrani@liu.se.

\section{References}

Asplund, M. et al. (2010) 'Wireless Ad Hoc Dissemination for Search and Rescue'. 7th International ISCRAM Conference. http://www.iscram.org/ISCRAM2010/Papers/214Asplund_etal.pdf.

Boden Municipal Rescue Service (2006) Logbook from the Bodträskfors Fire, 2006. Unpublished document.

Comfort, L.K. (2007) ‘Asymmetric Information Processes in Extreme Events'. In D.E. Gibbons (ed.). Communicable Crises: Prevention, Response, and Recovery in the Global Arena. Charlotte, NC: Information Age Publishing, pp. 137-68. 
Denning, P. (2006) 'Hastily Formed Networks'. Communications of the ACM. 49(4), pp. 1520.

Denning, P. and R. Hayes-Roth (2006) 'Decision Making in Very Large Networks'. Communications of the ACM. 49(11), pp. 19-23.

Endsley, M.R. (1988) 'Situation Awareness Global Assessment Technique (SAGAT)'. Proceedings of the National Aerospace and Electronics Conference, pp. 789-95.

Klein, G. and R. Calderwood (1991) 'Decision Models: Some Lessons from the Field'. IEEE Transactions on Systems Man and Cybernetics. 21(5), pp. 1018-26.

Klein, G. et al. (2005) 'Problem Detection'. Cognition, Technology \& Work. 7(1), pp. 14-28.

Kruke, B.I. and O.E. Olsen (2011) 'Knowledge Creation and Reliable Decision-making in Complex Emergencies'. Disasters. 36(2), pp. 212-32.

Landgren, J. (2004) 'Fire Crew Enroute Sensemaking in Emergency Response'. Proceedings of ISCRAM 2004. 87-92.

Leonard, H. and A. Howitt (2010) 'Organising Response to Extreme Emergencies: The Victorian Bushfires of 2009'. Australian Journal of Public Administration. 69(4), pp. 372-86.

Lundberg, J. and M. Asplund (2011) 'Communication Problems in Crisis Response'. Proceedings of the 8th International ISCRAM Conference. http://www.iscramlive.org/ISCRAM2011/proceedings/papers/137.pdf.

Lundberg, J. and B. Johansson (2006) 'Resilience, Stability and Requisite Interpretation in Accident Investigations'. Proceedings of 2nd Resilience Engineering Symposium, pp. 191-98.

Reason, J. (1997) Managing the Risks of Organizational Accidents. Burlington, VT: Ashgate. SRSA (Swedish Rescue Services Agency) (2006) 'Skogsbrand i fokus'. Boden: Räddings Verket, Bodens kommun and Länsstyrelsen i Norrbottens Län.

https://www.msb.se/Upload/Utbildning_och_ovning/Konferenser_seminarier/Dokumenta tion/Skogsbrand/Boden_2006/Boden\%202006\%20-\%20Skogsbrand\%20i\%20fokus.pdf.

Stanton, N.A. et al. (2009) 'Genotype and Phenotype Schemata and Their Role in Distributed Situation Awareness in Collaborative Systems'. Theoretical Issues in Ergonomics Science. 10(1), pp. 43-68.

Turner, B.A. (1978) Man-made Disasters. London: Wykeham.

Vennberg, M.N. (2006) 'Documentation from the Bodträskfors fire [in Swedish]'. Boden: Voluntary Resource Group. http://www.civil.se/wpcontent/blogs.dir/1/files/2012/03/frg_rapport_brand_.pdf.

Webb, G. (2004) 'Role Improvising during Crisis Situations'. International Journal of Emergency Management. 2(1), pp. 47-61.

Weick, K. (1993) 'The Collapse of Sensemaking in Organizations: The Mann Gulch Disaster'. Administrative Science Quarterly. 38(4), pp. 628-52.

Westrum, R. (2006) 'All Coherence Gone: New Orleans as a Resilience Failure'. 2nd Resilience Engineering Symposium, pp. 333-41.

Woods (2006) 'Essential Characteristics of Resilience'. In E. Hollnagel, D.D. Woods and N. Leveson (eds.). Resilience Engineering: Concepts and Precepts. Aldershot: Ashgate. 